\title{
Cadmium Mixing Behavior in Estuaries: Redox Controls on Removal and Mobilization
}

\author{
Kuo-Tung Jiann ${ }^{1,2, *}$ and Peng $\mathrm{Ho}^{2}$ \\ ${ }^{1}$ Department of Oceanography, National Sun Yat-sen University, Kaohsiung, Taiwan \\ ${ }^{2}$ Institute of Marine Geology and Chemistry, National Sun Yat-sen University, Kaohsiung, Taiwan \\ Received 14 August 2013, revised 31 March 2014, accepted 1 April 2014
}

\begin{abstract}
This study investigates various hydrological and redox conditions controlling phase transformation, removal and remobilization of $\mathrm{Cd}$ in three different estuaries in Taiwan. It was found that $\mathrm{Cd}$ mixing patterns in estuarine waters are controlled mainly by redox conditions and salinity. In a highly urbanized estuary segment low oxygen conditions caused sulfide production and the formation of stable Cd sulfide minerals. In oxygen-replete waters [dissolved oxygen (DO) $>200 \mu \mathrm{M}$ ], high concentrations of $\mathrm{Mn}$ (II), likely from exchange with bottom sediments were oxidized into Mn oxides, on which Cd is adsorbed. However, in the lower estuary regions elevated chloride concentrations are likely able to compete for Cd, with large proportions of $\mathrm{Cd}$ becoming complexed with chloride. The stable $\mathrm{Cd}$ sulfide minerals, resistant to oxidation in estuaries having short flushing time, are likely settling out and depositing into bottom sediments. Reversible Cd adsorption onto Mn oxides can enhance Cd mobility in lower estuary and coastal regions where Cd chloro-complexes form, resulting in greater Cd transport fluxes into the ocean.
\end{abstract}

Key words: Cadmium, Manganese, Dissolved and particulate phases, Estuarine chemistry, Removal, Remobilization

Citation: Jiann, K. T. and P. Ho, 2014: Cadmium mixing behavior in estuaries: Redox controls on removal and mobilization. Terr. Atmos. Ocean. Sci., 25, 655-664, doi: 10.3319/TAO.2014.04.01.01(Oc)

\section{INTRODUCTION}

Cadmium is a toxic element that can be bioaccumulated along food chains via trophic transfers, thus posing threats to aquatic organisms and human health (Rainbow 2007; Cassis et al. 2011; Liao et al. 2011; Taylor and Maher 2012). Cd uptake by both waterborne and diet borne routes have been reported (Alquezar et al. 2008; Cassis et al. 2011), with labile forms of $\mathrm{Cd}$ (ionic or weakly complexed) more mobile and more bioavailable (Degryse et al. 2006).

On a global scale, rivers are the predominant transport route for $\mathrm{Cd}$ whose concentrations are strongly influenced by anthropogenic activities from the continent to the ocean. $\mathrm{Cd}$ transport behavior in estuarine waters has been classified from mostly addition (Dai et al. 1995; Wen et al. 1999; Chiffoleau et al. 2001; Martino et al. 2002; Tang et al. 2002; Garnier and Guieu 2003; Waeles et al. 2005; Waeles et al. 2008;), to varying extents of removal (Paucot and Wollast 1997; Zwolsman et al. 1997; Jiann et al. 2005; Chaudry

\footnotetext{
* Corresponding author

E-mail:ktjiann@fac.nsysu.edu.tw
}

and Zwolsman 2008; Wen et al. 2011), resulting in modified $\mathrm{Cd}$ net fluxes out of estuaries into the ocean. The $\mathrm{Cd}$ removal features described above have been attributed to the formation of metal sulfides (Jiann et al. 2005) and adsorption onto $\mathrm{Fe}$ - and $\mathrm{Mn}$ oxides in suspended matter and sediments (Turner et al. 2008; Wen et al. 2008b). Cd also forms chloro-complexes when high concentrations of chloride are present, as is the case in lower estuary and coastal regions. $\mathrm{Cd}$ adsorbed onto particles can be partly desorbed and remobilized (Wen et al. 1999; Garnier and Guieu 2003; Waeles et al. 2004; Wen et al. 2008b), making Cd more mobile and potentially bioavailable to aquatic organisms.

There are many urbanized river/estuarine systems in the world where humans produce high domestic wastewater discharge, and consequently, low oxygen conditions that lead to suboxic to anoxic waters (Martino et al. 2002; Jiann et al. 2005; Chaudry and Zwolsman 2008). Cd behavior in suboxic waters becomes more complex by the presence of reduced forms of Mn that can be oxidized into Mn oxides when oxygen-rich waters from the coast are supplied to 
estuaries by tidal mixing. Under anoxic conditions the presence of sulfides will cause $\mathrm{Cd}$ removal from the water as sulfide minerals (Jiann et al. 2005).

Although Cd distribution in estuaries has been studied previously (see references above), its removal and adsorption mechanisms have not been directly related to the key controlling parameters beyond lab-scale studies. To this end, this study used water samples from three estuaries with different hydrochemical conditions, especially redox conditions, to investigate the mixing behavior of $\mathrm{Cd}$.

\section{MATERIALS AND METHODS}

Water samples were collected from three estuaries (Fig. 1) with different hydrological and varying redox conditions. The Danshuei (DS) River Estuary is located in the highly urbanized metropolitan (6-million population) area of Taipei with some small-scale industry in its watershed. The DS Estuary is a macrotidal, partially to well- mixed estuary with high nutrient loading, leading to sub-oxic to anoxic conditions in the upper estuary (Wen et al. 2008a). The two sampling events reported in this study for the DS River Estuary represent wet (July 2001) and dry (May 2002) seasons (Wen et al. 2008a). The Tsengwen (TW) River flows through mostly agricultural plains and several townships in southwestern Taiwan. Its estuarine characteristic is between a salt wedge estuary and a partially mixed estuary. Flowing through plains results in segments of the estuary having stagnant water under low-flow conditions. The Gaoping (GP) River is a typical mountainous river (slope 1/150) with its watershed including parts of the 3-million population metropolitan area of Kaohsiung in its lower reaches. The GP River is one of the most extensively used watersheds in Taiwan, and its lower reaches form a salt wedge estuary. The TW and
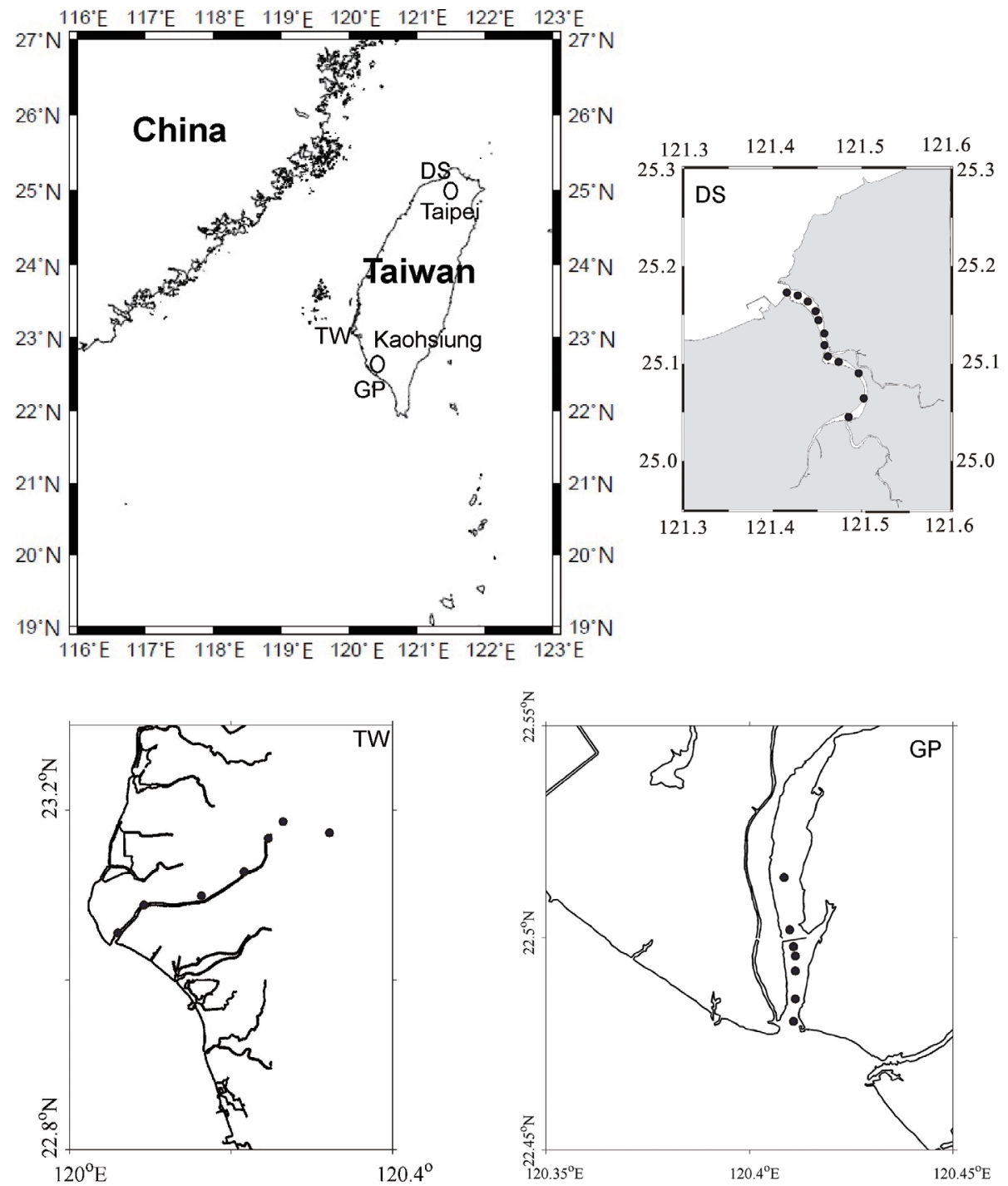

Fig. 1 Regional maps of the Danshuei (DS) River, Tsengwen (TW) River, and Gaoping (GP) River Estuaries, and locations of these estuaries in Taiwan. 
GP estuaries were sampled in February and March, 2009, respectively (for illustration purposes, because flow rates in the two rivers peak only after sudden intensive precipitation events such as typhoons).

Water samples for dissolved constituent determination were collected from each estuary under strict "clean sampling" guidelines (Wen et al. 1999; Jiann and Presley 2002) by pumping estuarine waters $(\sim 30-50 \mathrm{~cm}$ depth) directly through Teflon tubing and a $0.45 \mu \mathrm{m}$ capsule filter (Osmonics, Westborough, MA, USA) into acid-cleaned low-density polyethylene bottles (LDPE, Nalgene). For the collection of suspended particulate matter (SPM) a subsample was collected through the same sampling assemblage by bypassing the filtration system. Particles were collected by vacuum filtration onto polycarbonate membrane filters $(0.4 \mu \mathrm{m}$, Nuclepore) that had been acid-cleaned and weighed. Only surface waters were collected in order to ensure that the samples were in the tidal ranges. The results obtained allowed for the assessment of estuarine processes.

Filtered water samples were acidified $\left(2 \mathrm{~mL}\right.$ of $\mathrm{NHO}_{3}$, Seastar Baseline grade) to $\mathrm{pH}<2$ immediately after sample collection and stored in coolers. Once returned to the lab, the samples were transferred to Teflon bottles in a class100 laminar flow bench, UV-irradiated (8 lamps of $15 \mathrm{~W}$ each for 24 hours) to liberate Cd and Mn (Ostapczuk 1993; Wen et al. 1999; Jiann and Presley 2002), and preconcentrated on Chelex-100 resins $\left(\mathrm{NH}_{4}{ }^{+}\right.$-form after acid cleaning, Bio-Rad, 100 - 200 mesh), as described in earlier studies (Jiann and Presley 2002; Jiann et al. 2009). After a washing step to eliminate major cations $(\mathrm{Na}, \mathrm{K}, \mathrm{Mg}, \mathrm{Ca}), 7 \mathrm{~mL}$ of $2 \mathrm{~N} \mathrm{HNO}_{3}$ (Seastar, Baseline grade) was used to elute $\mathrm{Cd}$ and $\mathrm{Mn}$ from the column ( $\sim \mathrm{mL}$ collected due to shrinking of the Chelex-100 resins), resulting in a preconcentration factor of $\sim 125$ from $\sim 1$-L samples. Blanks (milli-Q water) and standard reference material (SLEW-3 estuarine water, from National Research Council of Canada) were processed along with samples for quality control and quality assurance purposes.

The filters on which SPM was retained were freezedried and weighed to yield SPM concentration. The particles on the filters were then totally digested by heating in Teflon vessels, with the addition of nitric acid, hydrofluoric acid and boric acid (Lauenstein and Cantillo 1998). Blanks (blank filters with reagents) and standard reference material MESS-3 (marine sediment, from National Research Council of Canada) were processed together with the samples in order to assess contamination control and digestion efficiency.

Additional sets of SPM samples were collected during our visits to the TW (February and July, 2009) and GP (March and July, 2009) Estuaries in order to conduct leaching experiments following the method developed by Landing and Lewis (1991) to elucidate the $\mathrm{Cd}$ and Mn distribution in SPM. Membrane filters were sequentially leached using $25 \%$ acetic acid and then aqua regia to obtain the metal fractions associated with surface adsorption (exchangeable fractions), and $\mathrm{Fe}$ - and $\mathrm{Mn}$-oxides and organic matter, respectively.

$\mathrm{Cd}$ concentration determination was performed on a graphite furnace atomic absorption spectrometer (Perkin Elmer AAnalyst 600), and Mn using a flame atomic absorption spectrometer (Perkin Elmer AAnalyst 200). The detection limits for dissolved and particulate $\mathrm{Cd}$ concentrations were 2 $\mathrm{pM}$ and $0.005 \mu \mathrm{g} \mathrm{g}^{-1}$, respectively, and $0.5 \mathrm{nM}$ and $0.5 \mu \mathrm{g} \mathrm{g}^{-1}$ for Mn. Blanks were all below the detection limits and recoveries for SLEW-3 and MESS-3 were 106\% (Cd) and 98\% $(\mathrm{Mn})$, and $102 \%$ (Cd and $\mathrm{Mn})$, respectively (Table 1).

Salinity was measured in the field using a portable conductivity meter (WTW). Dissolved oxygen (DO) concentrations were determined according to a colorimetric method (Pai et al. 1993) following fixation of DO in the field by adding Winkler reagents immediately after sampling.

\section{RESULTS AND DISCUSSION}

\subsection{Redox Conditions}

Estuarine processes in the DS Estuary are strongly influenced by freshwater input, tides and anthropogenic perturbations (Wen et al. 2008a). The upper DS Estuary is under suboxic to anoxic conditions except after very high precipitation events that lead to elevated river discharges and consequently higher DO concentrations (Jiann et al.

Table 1. Analytical results of estuarine water reference material (SLEW-3) and marine sediment reference material (MESS-3).

\begin{tabular}{ccc|cc}
\hline & \multicolumn{2}{c|}{ SLEW-3 $\left(\boldsymbol{\mu g} \mathbf{L}^{-\mathbf{1}}, \mathbf{n}=\mathbf{6}\right)$} & \multicolumn{2}{c}{ MESS-3 $\left(\mathbf{m g ~ k g}^{-\mathbf{1}}, \mathbf{n}=\mathbf{6}\right)$} \\
\cline { 2 - 5 } & $\mathbf{C d}$ & $\mathbf{M n}$ & $\mathbf{C d}$ & $\mathbf{M n}$ \\
\hline Certified & 0.048 & 1.61 & 0.24 & 324 \\
Std. dev. & 0.004 & 0.22 & 0.01 & 12 \\
Observed mean & 0.051 & 1.57 & 0.24 & 329 \\
Std. dev. & 0.004 & 0.12 & 0.01 & 12 \\
\hline Recovery $(\%)$ & 106 & 98 & 102 & 102 \\
\hline
\end{tabular}


2005; Wen et al. 2008a). However, surface waters at the river mouth are mostly oxygen saturated because of exchanges with oxygen-replete coastal waters. Therefore, redox interfaces present in the DS Estuary are influenced by the varying magnitude and duration of tidal inflows from coastal seawater. In May 2002, DO concentrations in the upper DS Estuary were near complete depletion and as low as $40 \mu \mathrm{M}$ in July 2001 (Fig. 2). For waters in the TW Estuary, DO concentrations were high and remained in a narrow range $(200-250 \mu \mathrm{M})$. DO concentrations in waters of the GP Estuary $(135-220 \mu \mathrm{M})$ showed a much different distribution pattern than the other two estuaries, with higher DO concentrations in the upper reaches and significantly lower ones in the lower estuary. Oxygen saturation rates ranged from $\sim 0-100 \%$ in the DS Estuary, $80-100 \%$ in the TW, and $60-80 \%$ in the GP systems. Various redox conditions in the waters of these three estuaries were observed, in which, due to the urbanized watershed of the DS Estuary and having at least part of the estuaries with stagnant water in the TW and GP systems, parts of all three estuaries were observed to be substantially oxygen depleted.

Also shown in Fig. 2 are SPM distributions in the three estuaries. Except for waters in the upper DS Estuary collected in July 2001 (wet season) when SPM concentrations were as high as $\sim 140 \mathrm{mg} \mathrm{L}^{-1}$, SPM concentrations were in general near or $<20 \mathrm{mg} \mathrm{L}^{-1}$.

\subsection{Cd Distribution}

Cd distribution patterns in the three estuaries showed distinctively different spatial and temporal variability (Fig. 3). In the DS Estuary, both addition and removal mixing behaviors were observed for dissolved $\mathrm{Cd}$. Evidence for drastic removal of dissolved Cd in the upper DS Estuary can be gleaned from the concave mixing curve, with dissolved
Cd concentrations in mid-estuary being even lower than the coastal end-member concentrations. Furthermore, in the lower DS Estuary, dissolved Cd concentrations were much higher than in the particulate phase, while conservative mixing and slight addition behavior (i.e., convex curvature) were observed because removal of dissolved $\mathrm{Cd}$ was so extensive that dissolved Cd concentrations in the DS estuarine waters were often lower than those in coastal waters.

In the TW Estuary significant addition of dissolved $\mathrm{Cd}$ was found in the mid-estuarine region and the dissolved $\mathrm{Cd}$ pool was much greater than that in the particulate $\mathrm{Cd}$ phase (Fig. 3). In the GP Estuary dissolved Cd concentrations in the upper estuary were much lower than in the coastal region (Fig. 3) and an unusual inverse conservative mixing behavior of dissolved $\mathrm{Cd}$ was observed. In the upper GP Estuary, particulate $\mathrm{Cd}$ concentrations were higher than dissolved Cd concentrations and they showed a reverse distribution pattern along the salinity gradient.

\subsection{Mn Distribution}

$\mathrm{Mn}$, when it is present at elevated levels in the dissolved phase as $\mathrm{Mn}$ (II), is an indicator of suboxic conditions either in the water (Klinkhammer and McManus 2001) or in the bottom sediments (Chiffoleau et al. 1994; Roitz et al. 2002; Tovar-Sánchez et al. 2004). Mn(II) has a long residence time in waters owing to its slow oxidation kinetics (Davison 1993). In a laboratory-scale study freshly synthesized Mn oxide was shown to have a stronger affinity for Cd adsorption than $\mathrm{Fe}$ oxide and estuarine sediments (Turner et al. 2008). Therefore, Mn oxides formed in waters can provide a carrier phase for $\mathrm{Cd}$ in estuarine waters (Wen et al. 2008b), provided its abundance is high enough. Thus, it becomes necessary to understand the distribution and partitioning of $\mathrm{Mn}$ in order to further relate it to $\mathrm{Cd}$ behavior in estuarine waters.
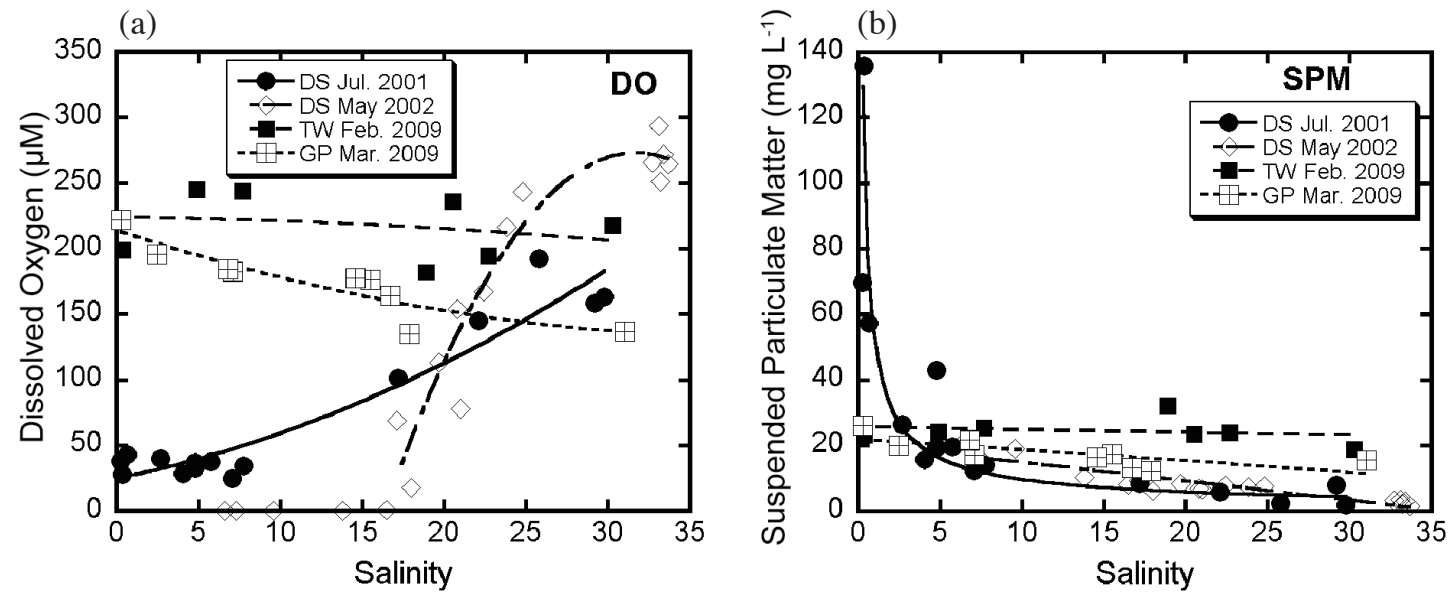

Fig. 2 Distribution of (a) dissolved oxygen (DO) and (b) suspended particulate matter (SPM) along salinity gradients in the three estuaries (total 4 cruises shown). Because dissolved and particulate phases do not behave the same, distribution patterns at times do not show typical estuarine behavior. Therefore, the fitted curves displayed in the figures are for visual purposes. 

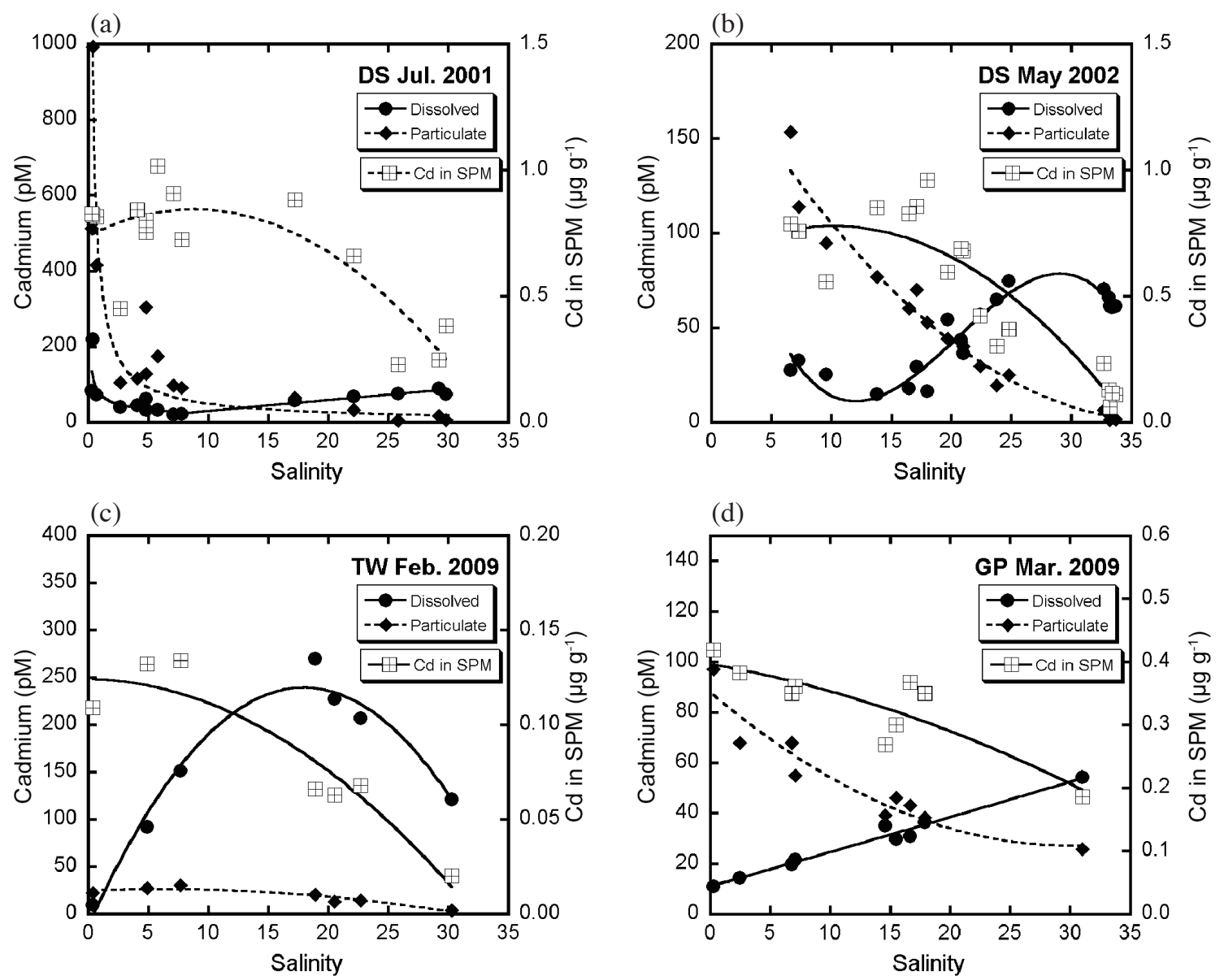

Fig. 3 Distribution of dissolved and particulate Cd along salinity gradients in the Danshuei River Estuary [(a) Jul 2001, (b) May 2002], the Tsengwen River Estuary (c), and the Gaoping River Estuary (d). Because dissolved and particulate phases do not behave the same, distribution patterns at times do not show typical estuarine behavior. Therefore, the fitted curves displayed in the figures are for visual purposes.

Elevated dissolved Mn concentrations and different estuarine mixing behaviors were observed in the three estuaries (Fig. 4). Dissolved Mn concentrations ranged from 27 - $2800 \mathrm{nM}$ (July 2001) and from 266 - $4650 \mathrm{nM}$ (May 2002) in the DS Estuary, from $246-2537 \mathrm{nM}$ in the TW Estuary (February 2009), and from 214 - $8547 \mathrm{nM}$ in the GP Estuary (March 2009). Mn concentrations in SPM (mass/mass) also showed large variations, ranging from $368-3106 \mu \mathrm{g} \mathrm{g}^{-1}$ (July 2001) and from 110 - $5153 \mu \mathrm{g} \mathrm{g}^{-1}$ (May 2002) in the DS Estuary, from $1097-2329 \mu \mathrm{g} \mathrm{g}^{-1}$ in the TW Estuary, and from $1881-10317 \mu \mathrm{g} \mathrm{g}^{-1}$ in the GP Estuary.

These variations in dissolved $\mathrm{Mn}$ concentrations were primarily due to dilution effects from estuarine mixing, but also caused by in situ Mn oxide formation, especially in the oxygen-replete lower estuarine regions. This phenomenon is further indicated by the progressive increases in Mn concentrations in SPM (Fig. 4) with increasing salinity in the lower DS Estuary. The Mn oxide formation is a function of DO concentration, as particulate Mn concentrations were significantly elevated when DO concentration was higher than $200 \mu \mathrm{M}$ regardless of the salinity (Fig. 5a), at levels above average crustal abundance $\left(\sim 1000 \mu \mathrm{g} \mathrm{g}^{-1}\right)$, reflecting the strong hypoxic (more oxygen-deplete) conditions in the DS system relative to the other two estuaries. The TW and GP estuarine waters also had relatively high DO concentrations and consequently higher particulate $\mathrm{Mn}$ concentrations (1000 - $10000 \mu \mathrm{g} \mathrm{g}^{-1}$ ), especially in the upper estuaries. However, largely due to the decreases in dissolved Mn and corresponding increases in particulate $\mathrm{Mn}$ concentrations, the distribution coefficients $\left(\mathrm{K}_{\mathrm{d}}\right)$ of $\mathrm{Mn}$ in general increased along the salinity gradients, as shown in Fig. 5b.

\subsection{Cd Phase Partitioning Controls}

Depending on the hydrochemical variability (i.e., redox condition and salinity), $\mathrm{Cd}$ can be present in estuarine waters as Cd sulfides (Jiann et al. 2005), associated with colloidal material (Muller 1998; Wells et al. 1998), adsorbed on particulate matter, especially on Mn oxides (Turner et al. 2008; Wen et al. 2008b), and as complexes with chloride (Stumm and Morgan 1995). Owing to the low DO (Fig. 2) and low particulate Mn (Fig. 4) concentrations in the upper 
DS Estuary, the correspondingly high Cd concentrations in SPM (Fig. 3) were possibly due to the formation of Cd sulfides (Al-Farawati and van den Berg 1999; Jiann et al. 2005; Chaudry and Zwolsman 2008). During the dry season the

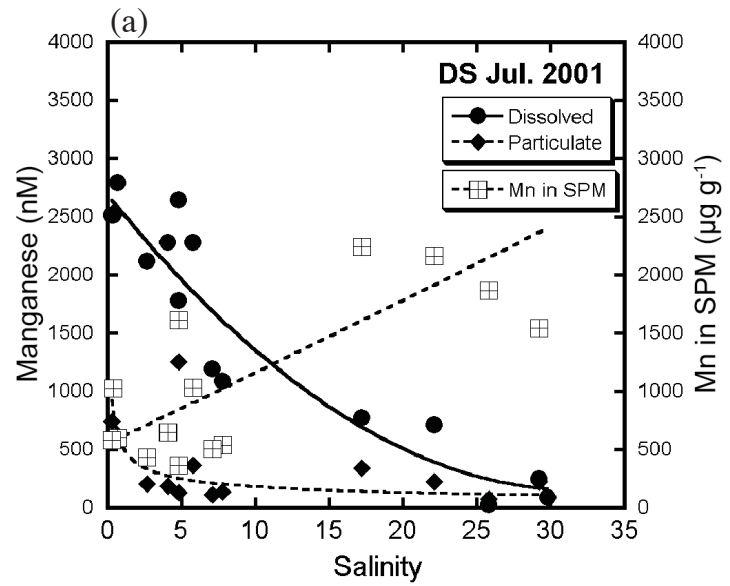

(c)

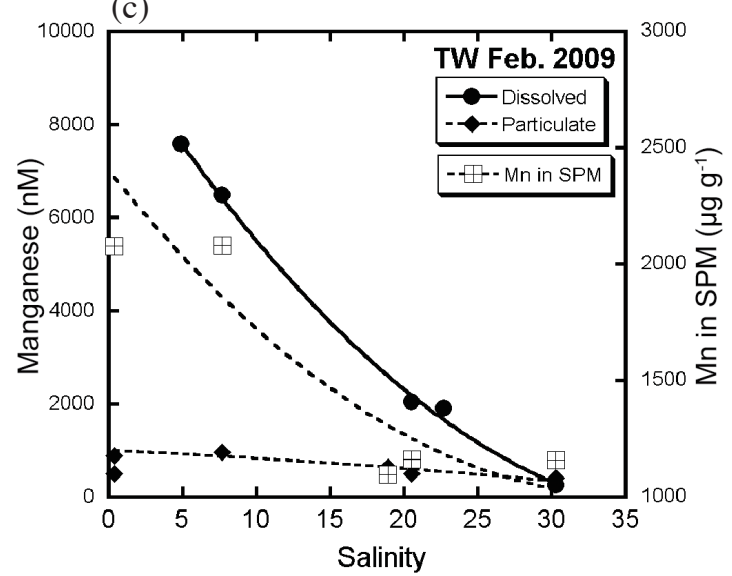

DS Estuary often had anoxic conditions in the upper estuarine waters (Jiann et al. 2005; Wen et al. 2008a), in which particulate $\mathrm{Cd}$ concentrations were higher than dissolved $\mathrm{Cd}$ concentrations, as shown in the case for May 2002. In the

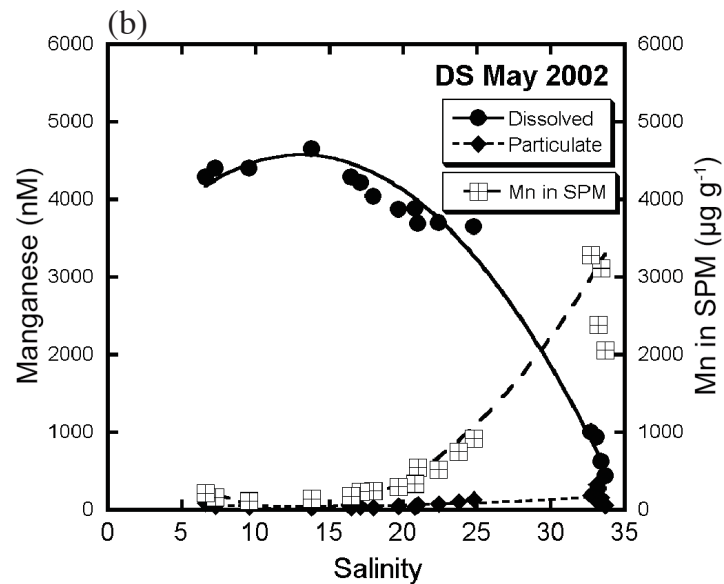

(d)

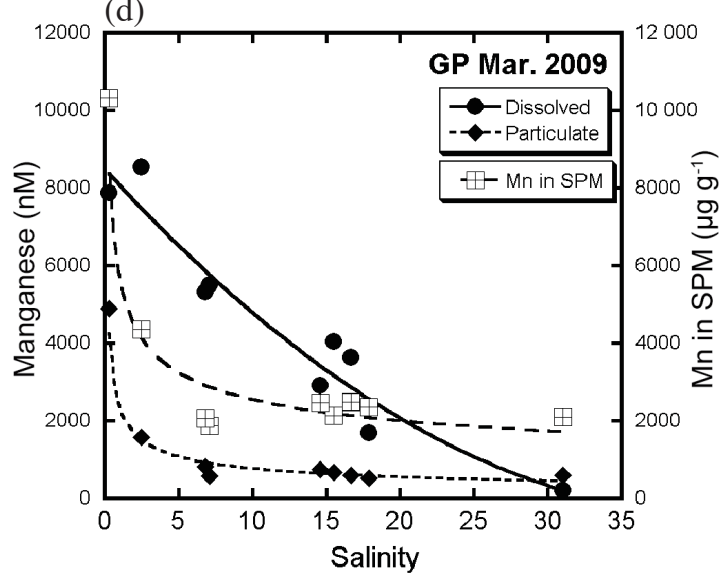

Fig. 4 Distribution of dissolved and particulate Mn along salinity gradients in the Danshuei River Estuary [(a) Jul 2001, (b) May 2002], the Tsengwen River Estuary (c), and the Gaoping River Estuary (d). Because dissolved and particulate phases do not behave the same, distribution patterns at times do not show typical estuarine behavior. Therefore, the fitted curves displayed in the figures are for visual purposes.
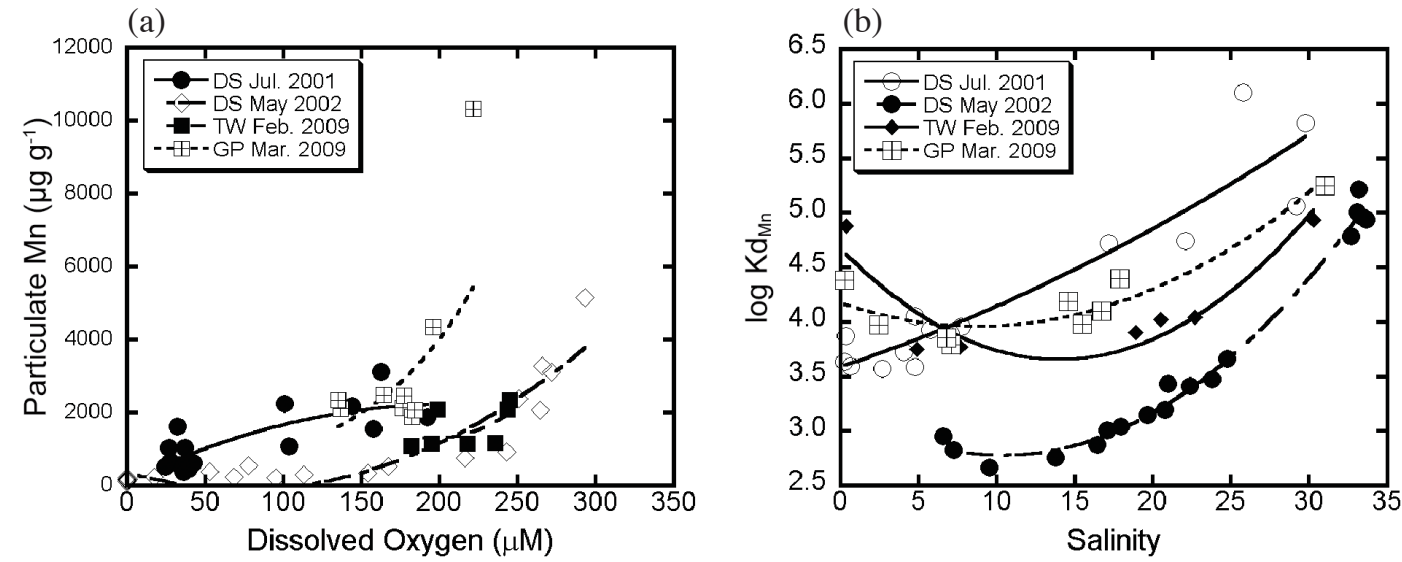

Fig. 5 (a) Relationship between particulate Mn (in SPM) and dissolved oxygen concentration and (b) distribution coefficient ( $\mathrm{K}_{d}$ ) for Mn along salinity gradients in the three estuaries studied. Because dissolved and particulate phases do not behave the same, distribution patterns at times do not show typical estuarine behavior. Therefore, the fitted curves displayed in the figures are for visual purposes. 
oxygen-deplete upper DS Estuary (Fig. 2), reduced sulfur species have been reported to be as high as $\sim 500 \mu \mathrm{M}$ (Jiann et al. 2005), a concentration so high that would lead to saturation with respect to metal sulfide complexes, including those of Cd. Samples measured for total dissolved sulfide concentrations in the anoxic waters collected in May 2002 were also high (100 - $300 \mu \mathrm{M}$ range, not shown). Cd sulfide would be in the colloidal size range when first formed (Jiann et al. 2005). However, this would result in a large proportion of $\mathrm{Cd}$ ending up in the particulate phase in the upper DS Estuary followed by substantial removal of dissolved Cd (Fig. 3) due to fast coagulation (colloidal pumping) processes (Honeyman and Santschi 1991; Wen et al. 1997). The extent of removal is more significant during the dry season when dissolved sulfides are present at hundred$\mu \mathrm{M}$ range (Jiann et al. 2005). Because of the high stability of metal sulfide minerals, this removal is not reversible in the time scale of days (common residence time of water in small estuaries) when oxygen is supplied from coastal water intrusion into the estuary (Simpson et al. 2000).

Owing to the anoxic characteristics of the upper DS Estuary, Mn oxide formation is not favored until very close to the coastal region. This is indicated by the comparably low particulate Mn concentrations compared to those of dissolved Mn concentrations, until reaching the lower estuary and coast (Fig. 4). Therefore, Cd adsorption onto Mn oxides is limited in the DS Estuary because of two different effects: (1) insignificant $\mathrm{Mn}$ oxide formation in the upper estuary, and (2) competition from chloride in the lower estuary. As a result, nearly all $\mathrm{Cd}$ in the lower DS estuarine waters $(\mathrm{S}>20)$ are present in the dissolved phase (Fig. 3).

In both the TW and GP Estuaries, which drain high slope, mountainous river systems, the salt wedge estuary type character produced some mildly under-saturated DO conditions. Contrary to the Cd mixing behavior in the DS Estuary, higher particulate $\mathrm{Cd}$ concentrations (relative to those in the lower estuaries) in the upper TW and GP Estuaries were concomitantly observed with high particulate $\mathrm{Mn}$ concentrations (Figs. 3 - 4). The waters in these two estuaries were not in anoxic condition and the formation of $\mathrm{Mn}$ oxides was evidenced by the presence of high particulate Mn concentrations (Fig. 4) in the upper- and mid-estuaries, thus providing adsorption carriers for $\mathrm{Cd}$. The mixing behavior of dissolved $\mathrm{Cd}$ in the TW Estuary was thus likely the result of $\mathrm{Cd}$ adsorption onto Mn oxides in the upper estuary and subsequent desorption in the lower estuary where chloride can compete for $\mathrm{Cd}$ adsorbed onto $\mathrm{Mn}$ oxides.

The association between particulate $\mathrm{Mn}$ and $\mathrm{Cd}$ adsorption was further displayed in a positive linear correlation, as illustrated in Fig. 6b, between exchangeable $\mathrm{Cd}$ and exchangeable $\mathrm{Mn}$ concentrations. Both $\mathrm{Cd}$ and $\mathrm{Mn}$ appeared mostly in the exchangeable fractions (> 80\%) in the two sample sets (February and March, 2009). In the DS Estuary samples in which only total particulate $\mathrm{Cd}$ and $\mathrm{Mn}$ concentrations were determined, an inverse correlation between $\mathrm{Cd}$ and $\mathrm{Mn}$ was found (Fig. 6a), with some exceptions due to re-suspension of bottom sediments (high SPM concentrations, Fig. 2) that contained lower particulate $\mathrm{Cd}$ concentrations in the July 2001 samples (values provided below). Contributions from re-suspended sediments toward the addition of dissolved $\mathrm{Cd}$ was considered limited in the DS and TW Estuaries owing to the facts that (1) the particulate Cd load in the TW Estuary was clearly much lower than the dissolved $\mathrm{Cd}$ concentrations (Fig. 3), and (2) $\mathrm{Cd}$ concentrations in TW Estuary sediments $\left(0.05-0.1 \mu \mathrm{g} \mathrm{g}^{-1}\right)$ were lower or comparable to particulate $\mathrm{Cd}$ concentrations and much lower in the DS Estuary (Jiann et al. 2005).

Plotting the composite data from all three estuaries (Fig. 7), it can be seen that particulate Cd concentrations decreased with increasing dissolved oxygen concentration because of: (1) sulfides were only present in anoxic, upper DS estuarine waters; and (2) desorption of $\mathrm{Cd}$ from mostly
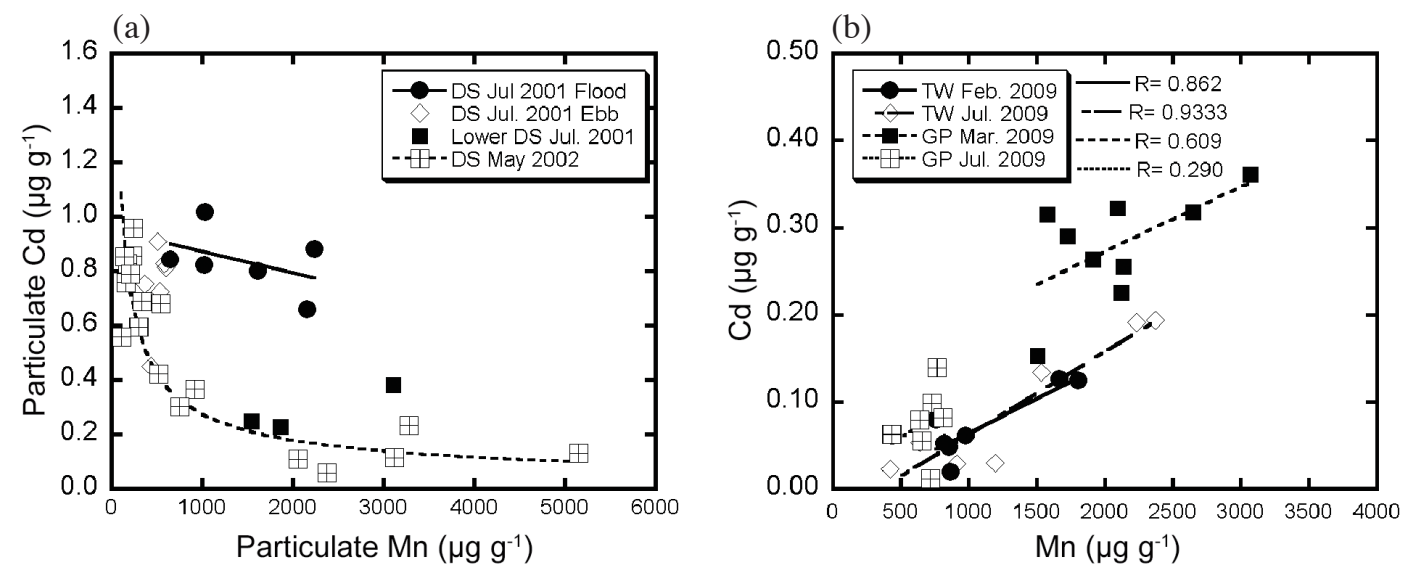

Fig. 6 Relationship between (a) particulate Cd and Mn (in SPM) concentration in the DS Estuary and (b) exchangeable Cd and exchangeable Mn concentrations in the TW and GP Estuaries. Because dissolved and particulate phases do not behave the same, distribution patterns at times do not show typical estuarine behavior. Therefore, the fitted curves displayed in the figures are for visual purposes. 

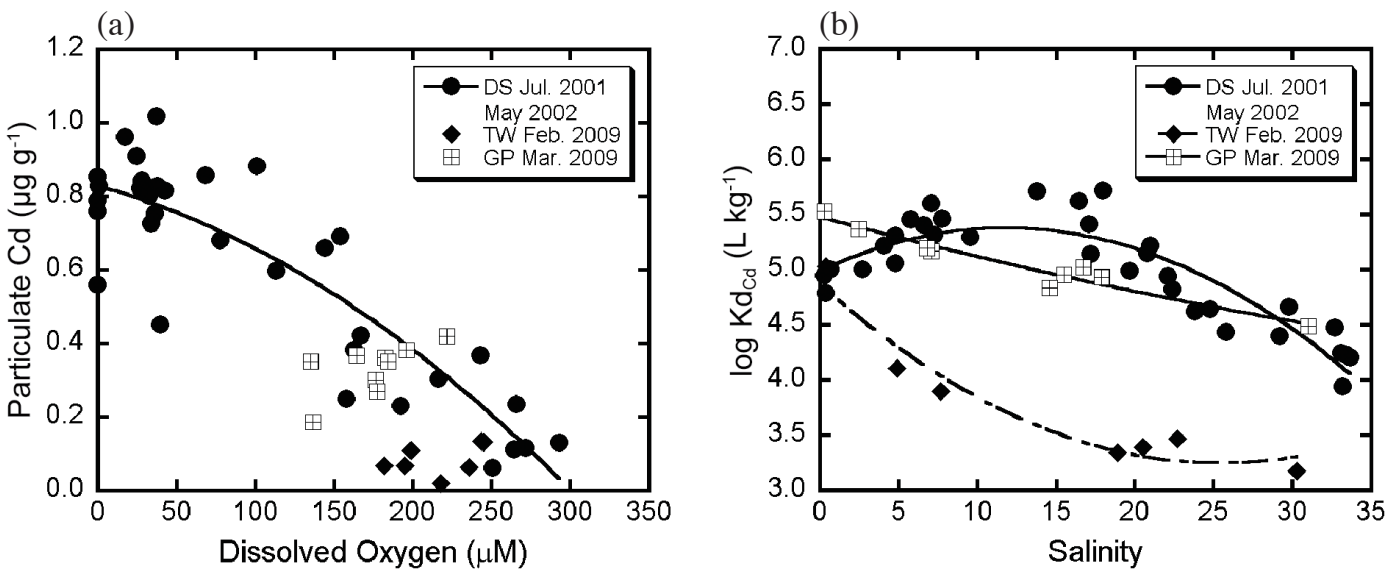

Fig. 7 (a) Relationship between particulate Cd (in SPM) and dissolved oxygen concentration and (b) distribution coefficient for Cd along salinity gradients in the three estuaries studied. Because dissolved and particulate phases do not behave the same, distribution patterns at times do not show typical estuarine behavior. Therefore, the fitted curves displayed in the figures are for visual purposes.

non-sulfidic particulate matter, including Mn oxides formed in oxygen-replete lower estuarine waters (> $150-200 \mu \mathrm{M}$, Fig. 4), as chloride concentrations increased allowing them to compete for $\mathrm{Cd}$. An apparent inverse correlation was observed in the partly anoxic DS Estuary for the redox condition (DO concentration) effect on $\mathrm{Cd}$ partitioning and no clear trends were found in the suboxic TW/GP systems (Fig. 7). This observation is in agreement with the distinctively different sulfur and $\mathrm{Mn}$ chemistry controlling for $\mathrm{Cd}$ behavior in the waters under anoxic and suboxic conditions. The lowDO, high-particulate Cd concentrations in the upper (anoxic) DS Estuary were caused by sulfides being produced to form sulfide minerals of $\mathrm{Cd}$.

As a result of decreasing particulate $\mathrm{Cd}$ and increasing dissolved $\mathrm{Cd}$ concentrations in the lower estuaries which gave results that are contrary to many other studies (Chiffoleau et al. 2001; Garnier and Guieu 2003; Wen et al. 2008b), distribution coefficient $\left(\mathrm{K}_{\mathrm{d}}\right)$ between particulate and dissolved phases of $\mathrm{Cd}$ displayed substantial decreases along salinity gradients in all three estuaries (Fig. 7b). The slightly elevated $K_{d}$ values in the upper DS Estuary were due to the formation of $\mathrm{Cd}$ sulfide minerals in the water, as reported earlier (Jiann et al. 2005). The changes in Cd concentrations in SPM and the corresponding $\mathrm{K}_{d}$ variation in the GP systems were minimal compared to the DS and TW Estuaries. Ultimately, variations in Cd solid-solution partitioning coefficients resulted from its association with Mn oxides, sulfides and/or $\mathrm{Cl}$ (salinity) in different parts of the estuaries.

\section{CONCLUSIONS}

Mixing behavior of $\mathrm{Cd}$ in estuarine waters is a result of the interplay between redox conditions and salinity (chloride concentration). In highly urbanized estuaries or river segments where oxygen can be completely consumed due to high domestic and industrial wastewater discharges, the presence of sulfides leads to the formation of Cd sulfide minerals that are initially colloidal in size but contribute rapidly to elevated $\mathrm{Cd}$ concentrations in suspended particles. The $\mathrm{CdS}$ minerals are stable within the average flushing time scales of estuaries and ultimately settle out and deposit into bottom sediments through flocculation processes. In suboxic waters the $\mathrm{Mn}(\mathrm{II})$ produced in the water and diffusing from bottom sediments will be oxidized to form Mn oxides onto which $\mathrm{Cd}$ can adsorb reversibly. This reversible $\mathrm{Cd}$ adsorption process onto oxides is reversed in the lower estuaries when salinity increases, as the strong affinity between $\mathrm{Cd}$ and chlorides results in elevated dissolved Cd concentrations from $\mathrm{Cd}$ desorption in the lower estuaries and coastal regions. These above mentioned processes create $\mathrm{Cd}$ being possibly removed and remobilized in the same estuary, depending on DO and salinity. The Cd sulfidic minerals can cause elevated sedimentary $\mathrm{Cd}$ concentrations (along with other trace metals) until they are exposed to the air over a long period of time (dredging and disposal), while the remobilization of $\mathrm{Cd}$ from adsorbed particulate matter will enhance the $\mathrm{Cd}$ fluxes being transported to the ocean.

Acknowledgements The authors would like to acknowledge that Dr. Peter H. Santschi and another anonymous Reviewer provided helpful comments that greatly improved this manuscript. This work was financially supported by the National Science Council of Taiwan through contracts NSC90-2119-M-002-016, NSC91-2119-M-002-031, NSC97-2611-M-110-007, NSC98-2611-M-110-006, and NSC101-2611-M-110-008.

\section{REFERENCES}

Al-Farawati, R. and C. M. G. van den Berg, 1999: Metalsulfide complexation in seawater. Mar. Chem., 63,331352, doi: 10.1016/S0304-4203(98)00056-5. [Link] 
Alquezar, R., S. J. Markich, and J. R. Twining, 2008: Comparative accumulation of ${ }^{109} \mathrm{Cd}$ and ${ }^{75} \mathrm{Se}$ from water and food by an estuarine fish (Tetractenos glaber). J. Environ. Radioact., 99, 167-180, doi: 10.1016/j. jenvrad.2007.07.012. [Link]

Cassis, D., P. Lekhi, C. M. Pearce, N. Ebell, K. Orians, and M. T. Maldonado, 2011: The role of phytoplankton in the modulation of dissolved and oyster cadmium concentrations in Deep Bay, British Columbia, Canada. Sci. Total Environ., 409, 4415-4424, doi: 10.1016/j. scitotenv.2011.06.014. [Link]

Chaudry, M. A. and J. J. G. Zwolsman, 2008: Seasonal dynamics of dissolved trace metals in the Scheldt Estuary: Relationship with redox conditions and phytoplankton activity. Estuaries Coasts, 31, 430-443, doi: 10.1007/ s12237-007-9030-7. [Link]

Chiffoleau, J. F., D. Cossa, D. Auger, and I. Truquet, 1994: Trace metal distribution, partition and fluxes in the Seine estuary (France) in low discharge regime. Mar. Chem., 47, 145-158, doi: 10.1016/03044203(94)90105-8. [Link]

Chiffoleau, J. F., D. Auger, E. Chartier, P. Michel, I. Truquet, A. Ficht, J. L. Gonzalez, and L. A. Romaña, 2001: Spatiotemporal changes in cadmium contamination in the Seine estuary (France). Estuaries, 24, 1029-1040, doi: 10.2307/1353015. [Link]

Dai, M., J. M. Martin, and G. Cauwet, 1995: The significant role of colloids in the transport and transformation of organic carbon and associated trace metals $(\mathrm{Cd}, \mathrm{Cu}$ and $\mathrm{Ni}$ ) in the Rhône delta (France). Mar. Chem., 51, 159175, doi: 10.1016/0304-4203(95)00051-R. [Link]

Davison, W., 1993: Iron and manganese in lakes. Earth-Sci. Rev.,34,119-163, doi: 10.1016/0012-8252(93)90029-7. [Link]

Degryse, F., E. Smolders, and R. Merckx, 2006: Labile Cd complexes increase $\mathrm{Cd}$ availability to plants. Environ. Sci. Technol., 40, 830-836, doi: 10.1021/es050894t. [Link]

Garnier, J. M. and C. Guieu, 2003: Release of cadmium in the Danube estuary: Contribution of physical and chemical processes as determined by an experimental approach. Mar. Environ. Res., 55, 5-25, doi: 10.1016/ S0141-1136(02)00107-1. [Link]

Honeyman, B. D. and P. H. Santschi, 1991: Coupling adsorption and particle aggregation: Laboratory studies of "colloidal pumping" using ${ }^{59} \mathrm{Fe}$-labeled hematite. Environ. Sci. Technol., 25, 1739-1749.

Jiann, K. T. and B. J. Presley, 2002: Preservation and determination of trace metal partitioning in river water by a two-column ion exchange method. Anal. Chem., 74, 4716-4724, doi: 10.1021/ac025626h. [Link]

Jiann, K. T., L. S. Wen, and P. H. Santschi, 2005: Trace metal $(\mathrm{Cd}, \mathrm{Cu}, \mathrm{Ni}$ and $\mathrm{Pb})$ partitioning, affinities and removal in the Danshuei River estuary, a macro-tidal, temporally anoxic estuary in Taiwan. Mar. Chem., 96, 293-313, doi: 10.1016/j.marchem.2005.03.001. [Link]

Jiann, K. T., L. S. Wen, and G. C. Gong, 2009: Distribution and behaviors of $\mathrm{Cd}, \mathrm{Cu}$, and $\mathrm{Ni}$ in the East China Sea surface water off the Changjiang Estuary. Terr. Atmos. Ocean. Sci., 20, 433-443, doi: 10.3319/ TAO.2008.05.09.01(Oc). [Link]

Klinkhammer, G. P. and J. McManus, 2001: Dissolved manganese in the Columbia River estuary: Production in the water column. Geochim. Cosmochim. Acta, 65, 2835-2841, doi: 10.1016/S0016-7037(01)00650-0. [Link]

Landing, W. M. and B. L. Lewis, 1991: Collection, Processing, and analysis of marine particulate and colloidal material for transition metals. In: Hurd, D. C. and D. Spencer (Eds.), Marine Particles: Analysis and Characterization, American Geophysical Union, Washington, D.C., 263-272, doi: 10.1029/GM063p0263. [Link]

Lauenstein, G. G. and A. Y. Cantillo, 1998: Sampling and analytical methods of the National Status and Trends Program Mussel Watch Project: 1993-1996 update. National Status and Trends Program for Marine Environmental Quality, NOAA/National Ocean Service/ Office of Ocean Resources Conservation and Assessment, Silver Spring, Maryland, 257 pp.

Liao, C. M., Y. R. Ju, W. Y. Chen, and B. C. Chen, 2011: Assessing the impact of waterborne and dietborne cadmium toxicity on susceptibility risk for rainbow trout. Sci.Total Environ., 409, 503-513, doi: 10.1016/j.scitotenv.2010.10.044. [Link]

Martino, M., A. Turner, M. Nimmo, and G. E. Millward, 2002: Resuspension, reactivity and recycling of trace metals in the Mersey Estuary, UK. Mar. Chem., 77, 171-186, doi: 10.1016/S0304-4203(01)00086-X. [Link]

Muller, F. L. L., 1998: Colloid/solution partitioning of metal-selective organic ligands, and its relevance to $\mathrm{Cu}$, $\mathrm{Pb}$ and $\mathrm{Cd}$ cycling in the Firth of Clyde. Estuar. Coast. Shelf Sci., 46, 419-437, doi: 10.1006/ecss.1997.0267. [Link]

Ostapczuk, P., 1993: Present potentials and limitations in the determination of trace elements by potentiometric stripping analysis. Anal. Chim. Acta, 273, 35-40, doi: 10.1016/0003-2670(93)80142-8. [Link]

Pai, S. C., G. C. Gong, and K. K. Liu, 1993: Determination of dissolved oxygen in seawater by direct spectrophotometry of total iodine. Mar. Chem., 41, 343-351, doi: 10.1016/0304-4203(93)90266-Q. [Link]

Paucot, H. and R. Wollast, 1997: Transport and transformation of trace metals in the Scheldt estuary. Mar. Chem., 58, 229-244, doi: 10.1016/S0304-4203(97)00037-6. [Link]

Rainbow,P.S., 2007: Trace metal bioaccumulation: Models, metabolic availability and toxicity. Environ. Int., 33, 
576-582, doi: 10.1016/j.envint.2006.05.007. [Link]

Roitz, J. S., A. R. Flegal, and K. W. Bruland, 2002: The biogeochemical cycling of manganese in San Francisco Bay: Temporal and spatial variations in surface water concentrations. Estuar. Coast. Shelf Sci., 54, 227-239, doi: 10.1006/ecss.2000.0839. [Link]

Simpson, S. L., S. C. Apte, and G. E. Batley, 2000: Effect of short-term resuspension events on the oxidation of cadmium, lead, and zinc sulfide phases in anoxic estuarine sediments. Environ. Sci. Technol., 34, 4533-4537, doi: 10.1021/es991440x. [Link]

Stumm, W. and J. J. Morgan, 1995: Aquatic Chemistry: Chemical Equilibria and Rates in Natural Waters, $3^{\text {rd }}$ Edition, John Wiley \& Sons, New York, 1040 pp.

Tang, D., K. W. Warnken, and P. H. Santschi, 2002: Distribution and partitioning of trace metals $(\mathrm{Cd}, \mathrm{Cu}, \mathrm{Ni}, \mathrm{Pb}$, $\mathrm{Zn)}$ in Galveston Bay waters. Mar. Chem., 78, 29-45, doi: 10.1016/S0304-4203(02)00007-5. [Link]

Taylor, A. M. and W. A. Maher, 2012: Exposure-doseresponse of Anadara trapezia to metal contaminated estuarine sediments. 1. Cadmium spiked sediments. Aquat. Toxicol., 109, 234-242, doi: 10.1016/j.aquatox.2011.09.014. [Link]

Tovar-Sánchez, A., S. A. Sañudo-Wilhelmy, and A. R. Flegal, 2004: Temporal and spatial variations in the biogeochemical cycling of cobalt in two urban estuaries: Hudson River Estuary and San Francisco Bay. Estuar. Coast. Shelf Sci., 60, 717-728, doi: 10.1016/j. ecss.2004.03.010. [Link]

Turner, A., S. M. Le Roux, and G. E. Millward, 2008: Adsorption of cadmium to iron and manganese oxides during estuarine mixing. Mar. Chem., 108, 77-84, doi: 10.1016/j.marchem.2007.10.004. [Link]

Waeles, M., R. D. Riso, J. F. Maguer, and P. Le Corre, 2004: Distribution and chemical speciation of dissolved cadmium and copper in the Loire estuary and North Biscay continental shelf, France. Estuar. Coast. Shelf Sci., 59, 49-57, doi: 10.1016/j.ecss.2003.07.009. [Link]

Waeles, M., R. D. Riso, and P. Le Corre, 2005: Seasonal variations of cadmium speciation in the Penzé estuary, NW France. Estuar. Coast. Shelf Sci., 65, 143-152, doi: 10.1016/j.ecss.2005.06.002. [Link]

Waeles, M., V. Tanguy, G. Lespes, and R. D. Riso, 2008:
Behaviour of colloidal trace metals $(\mathrm{Cu}, \mathrm{Pb}$ and $\mathrm{Cd})$ in estuarine waters: An approach using frontal ultrafiltration (UF) and stripping chronopotentiometric methods (SCP). Estuar. Coast. Shelf Sci., 80, 538-544, doi: 10.1016/j.ecss.2008.09.010. [Link]

Wells, M. L., P. B. Kozelka, and K. W. Bruland, 1998: The complexation of 'dissolved' $\mathrm{Cu}, \mathrm{Zn}, \mathrm{Cd}$ and $\mathrm{Pb}$ by soluble and colloidal organic matter in Narragansett Bay, RI. Mar. Chem., 62, 203-217, doi: 10.1016/ S0304-4203(98)00041-3. [Link]

Wen, L. S., P. H. Santschi, and D. Tang, 1997: Interactions between radioactively labeled colloids and natural particles: Evidence for colloidal pumping. Geochim. Cosmochim. Acta, 61, 2867-2878, doi: 10.1016/S00167037(97)00139-7. [Link]

Wen, L. S., P. Santschi, G. Gill, and C. Paternostro, 1999: Estuarine trace metal distributions in Galveston Bay: Importance of colloidal forms in the speciation of the dissolved phase. Mar. Chem., 63, 185-212, doi: 10.1016/S0304-4203(98)00062-0. [Link]

Wen, L. S., K. T. Jiann, and K. K. Liu, 2008a: Seasonal variation and flux of dissolved nutrients in the Danshuei Estuary, Taiwan: A hypoxic subtropical mountain river. Estuar. Coast. Shelf Sci., 78, 694-704, doi: 10.1016/j.ecss.2008.02.011. [Link]

Wen, L. S., K. W. Warnken, and P. H. Santschi, 2008b: The role of organic carbon, iron, and aluminium oxyhydroxides as trace metal carriers: Comparison between the Trinity River and the Trinity River Estuary (Galveston Bay, Texas). Mar. Chem., 112, 20-37, doi: 10.1016/j.marchem.2008.06.003. [Link]

Wen, L. S., P. H. Santschi, K. W. Warnken, W. Davison, H. Zhang, H. P. Li, and K. T. Jiann, 2011: Molecular weight and chemical reactivity of dissolved trace metals $(\mathrm{Cd}, \mathrm{Cu}, \mathrm{Ni})$ in surface waters from the Mississippi River to Gulf of Mexico. Estuar. Coast. Shelf Sci., 92, 649-658, doi: 10.1016/j.ecss.2011.03.009. [Link]

Zwolsman, J. J. G., B. T. M. van Eck, and C. H. van der Weijden, 1997: Geochemistry of dissolved trace metals (cadmium, copper, zinc) in the Scheldt estuary, southwestern Netherlands: Impact of seasonal variability. Geochim. Cosmochim. Acta, 61, 1635-1652, doi: 10.1016/S0016-7037(97)00029-X. [Link] 